\title{
Properties of Methane and Carbon Adsorbed at the Interface between Molten $\mathrm{NaBr}$ and
} $\mathrm{Ni}(111)$

Tarazkar, Maryam; Metiu, Horia; Kristoffersen, Henrik Høgh

Published in:

Journal of Physical Chemistry C

Link to article, DOI:

10.1021/acs.jpcc.0c11105

Publication date:

2021

Document Version

Peer reviewed version

Link back to DTU Orbit

Citation (APA):

Tarazkar, M., Metiu, H., \& Kristoffersen, H. H. (2021). Properties of Methane and Carbon Adsorbed at the Interface between Molten $\mathrm{NaBr}$ and $\mathrm{Ni}(111)$. Journal of Physical Chemistry C, 125, 39803987.

https://doi.org/10.1021/acs.jpcc.0c11105

\section{General rights}

Copyright and moral rights for the publications made accessible in the public portal are retained by the authors and/or other copyright owners and it is a condition of accessing publications that users recognise and abide by the legal requirements associated with these rights.

- Users may download and print one copy of any publication from the public portal for the purpose of private study or research.

- You may not further distribute the material or use it for any profit-making activity or commercial gain

- You may freely distribute the URL identifying the publication in the public portal

If you believe that this document breaches copyright please contact us providing details, and we will remove access to the work immediately and investigate your claim 


\title{
Properties of methane and carbon adsorbed at the interface between molten
}

\section{NaBr and Ni(111)}

\author{
Maryam Tarazkar $^{\mathrm{a}^{*}}$, Horia Metiu ${ }^{\mathrm{a}}$, Henrik H. Kristoffersen ${ }^{\mathrm{b}}$ \\ ${ }^{a}$ Department of Chemistry and Biochemistry, University of California-Santa Barbara, Santa \\ Barbara, CA, USA \\ ${ }^{\mathrm{b}}$ Department of Physics, Technical University of Denmark, 2800 Kgs. Lyngby, Denmark \\ *Corresponding author. Email: maryamtarazkar@ucsb.edu \\ *Corresponding author. Email: hhkri@dtu.dk
}

\begin{abstract}
Electronic structure calculations and constant temperature ab initio molecular dynamics simulations were used to study the molten $\mathrm{NaBr}-\mathrm{Ni}(111)$ interface. The presence of molten $\mathrm{NaBr}$ has a pronounced effect on the $\mathrm{Ni}(111)$ surface. For instance, the $\mathrm{Na}^{+}$and $\mathrm{Br}^{-}$ion concentrations are increased at the interface and Bader charge analysis shows that negative charge is transferred from $\mathrm{Br}^{-}$ions at the interface to the $\mathrm{Ni}(111)$ surface. The molten $\mathrm{NaBr}$ also destabilizes dissociated methane $\left({ }^{*} \mathrm{CH}+3 \mathrm{H}^{*}\right)$ adsorbed at the $\mathrm{NaBr}-\mathrm{Ni}(111)$ interface compared to dissociated methane adsorbed on $\mathrm{Ni}(111)$ without $\mathrm{NaBr}$. Carbon dimers $\left({ }^{*} \mathrm{C}_{2}\right)$ at the $\mathrm{NaBr}-\mathrm{Ni}(111)$ interface are found to be kinetically and thermodynamically unstable and dissociate into carbon atoms. Furthermore, carbon atoms initially placed at the $\mathrm{NaBr}-\mathrm{Ni}(111)$ interface or on the bare $\mathrm{Ni}(111)$ surface quickly diffuse into the $\mathrm{Ni}(111)$ slab. The molten $\mathrm{NaBr}$ increase the stability of atomic carbon in the subsurface region. Nickel nanoparticles would be excellent catalysts for methane pyrolysis if they did not rapidly coke. One goal of this study was therefore to investigate whether a molten salt would hinder or remove coke from the $\mathrm{Ni}(111)$ surface. Molten $\mathrm{NaBr}$ may help keep the $\mathrm{Ni}(111)$ surface clean of carbon and catalytically active by favoring subsurface carbon. It is however
\end{abstract}


questionable whether subsurface carbon is desirable, as it has been reported that dissolved carbon precipitates out of the nickel particles as carbon whiskers that block the catalyst bed.

Keywords: Pyrolysis, molten salt, nickel catalyst, methane activation, carbon formation, interfaces, ab initio molecular dynamics

\section{Introduction and Background}

Numerous papers have discussed the possibility of replacing carbon-based fuels with hydrogen to avoid $\mathrm{CO}_{2}$ generation. Currently the most widely practiced method of hydrogen production is steam reforming of methane or petroleum-based feedstocks. Unfortunately, to produce 50 million tons of hydrogen this method coproduces 300 million tons of $\mathrm{CO}_{2}$. This is not satisfactory if one intends to use hydrogen in a $\mathrm{CO}_{2}$-free economy. A possible alternative is hydrogen production by methane pyrolysis (reaction eq 1).

$\mathrm{CH}_{4}(\mathrm{~g}) \rightarrow \mathrm{C}(\mathrm{s})+2 \mathrm{H}_{2}(\mathrm{~g})$

In gas phase methane pyrolysis takes place at high temperature, with slow rate and it is used only if the goal is to make high quality carbon black. To perform the reaction efficiently one must have a catalyst. Unfortunately, the conventional solid, heterogeneous catalysts (e.g. Ni nanoparticles supported on alumina) are deactivated by the carbon produced in the reaction. ${ }^{1-3}$ The literature recommends that the catalyst should be reactivated by burning the coke, but this produces $\mathrm{CO}_{2}$ defeating the goal of having a $\mathrm{CO}_{2}$ free process.

A possible solution is to use a molten catalyst in a bubble column or a carbon catalyst in a fluidized bed. ${ }^{4-23}$ In a bubble column containing the molten catalyst the pyrolysis reaction takes place in a bubble traveling upward through the liquid. The carbon produced by pyrolysis is carried 
with the bubble and deposited on the surface of the melt. If the melt density is higher than that of carbon (in most cases it is) the carbon floats on the surface of the melt and can be removed by skimming. In this process each new bubble is in contact with a clean liquid-catalyst surface and coking is no longer a problem. This arrangement requires that the liquid in the bubble column is a good catalyst. Recently, it has been shown that molten $\mathrm{Ni}-\mathrm{Bi}^{24}{ }^{24}$ molten $\mathrm{Cu}-\mathrm{Bi}^{25}$ molten $\mathrm{MnCl}_{2-}$ $\mathrm{KCl},{ }^{26}$ and molten tellurium ${ }^{27}$ are all good catalysts for methane pyrolysis at $\sim 1000^{\circ} \mathrm{C}$.

In this article we explore another paradigm. Clean Ni nanoparticles are highly active for methane pyrolysis, but they coke very rapidly and lose their activity. Ni nanoparticles alone are therefore not good catalysts for methane pyrolysis. The question we ask here is whether a suspension of Ni nanoparticles in a molten salt might be a good catalyst which does not coke. This might happen if the salt adheres to the surface more readily than the carbon or if the carbon atom formed by pyrolysis prefers to be in the salt rather than the salt-Ni interface. To answer this question, we use ab initio molecular dynamics (AIMD) and density functional theory (DFT) to simulate the properties of the interface between molten $\mathrm{NaBr}$ and a $\mathrm{Ni}(111)$ slab. We choose $\mathrm{NaBr}$, because it is a simple alkali halide salt and because we hope that the interactions between $\mathrm{Br}^{-}$and the $\mathrm{Ni}(111)$ surface have intermediate strength such that surface adsorbates are destabilized without the surface being poisoned by the anions. First, we examine the $\mathrm{NaBr}-\mathrm{Ni}(111)$ interface and calculate the effect of the salt on the $\mathrm{Ni}(111)$ surface. In particular, we look at how the concentration of the ions depends on the distance from the surface and how the electron charge is redistributed when $\mathrm{NaBr}$ and $\mathrm{Ni}(111)$ interact with each other. The analysis shows that there is an increased concentration of both $\mathrm{Na}^{+}$and $\mathrm{Br}^{-}$ions at the interface and that negative charge is transferred from the $\mathrm{Br}^{-}$ions at the interface to the $\mathrm{Ni}(111)$ surface. 
We further investigate the stability of methane, dissociated methane, carbon atom(s), and carbon dimers at the $\mathrm{NaBr}-\mathrm{Ni}(111)$ interface. We find that placing a methane molecule at the $\mathrm{NaBr}-$ $\mathrm{Ni}(111)$ interface leads to dissolution of methane into the salt. However, moving the $\mathrm{CH}_{4}$ molecule from gas phase into the salt is still energetically uphill and we therefore expect a very low methane solubility in the salt. Dissociated methane $\left({ }^{*} \mathrm{CH}+3 \mathrm{H}^{*}\right)$ adsorbed at $\mathrm{NaBr}-\mathrm{Ni}(111)$ interface is more stable than molecular methane dissolved in the $\mathrm{NaBr}$ salt, but less stable than dissociated methane on a bare $\mathrm{Ni}(111)$ surface. The presence of $\mathrm{NaBr}$ therefore destabilizes dissociated methane adsorbed on the $\mathrm{Ni}(111)$ surface and restrict access to the surface because of its low methane solubility. However, we do not believe this rule out using solid Ni particles suspended in $\mathrm{NaBr}$ melt as a methane pyrolysis catalyst. This is because the adsorbed dissociated methane is more stable than dissociated methane adsorbed on other known methane pyrolysis catalyst and because a rising bubble containing methane will come in contact with the $\mathrm{Ni}$ particles so it is not necessary that methane is soluble in the melt.

Carbon atoms that start at the $\mathrm{NaBr}-\mathrm{Ni}(111)$ interface is found to migrate rapidly into the subsurface of the $\mathrm{Ni}(111)$ slab. Given a choice between the metal and the salt the carbon atom prefers to go into the metal. We have also examined the behavior of a $\mathrm{C}_{2}$ dimer species placed at the metal-salt interface. The $\mathrm{C}_{2}$ species dissociates rapidly, and the atoms formed by dissociation also migrate into the bulk.

It has been reported ${ }^{28}$ that $\mathrm{Ni}$ surfaces stay catalytically active for $\mathrm{C}-\mathrm{H}$ bond breaking as long as carbon dissolves into the $\mathrm{Ni}$ metal rather than accumulating on the Ni surface. Placing Ni nanoparticles in molten salt could therefore help keep the Ni(111) surface clean of carbon and catalytically active. The solubility of carbon in Ni nanoparticles is likely substantial, as nickel carbide has been reported to be thermodynamically stable above $510^{\circ} \mathrm{C}$ (although the structure and 
composition of the nickel carbide is not known). ${ }^{29-30}$ Unfortunately, the study $\left[{ }^{28}\right]$ also states that dissolved carbon is not desirable, because the carbon eventually precipitates out of the nickel particles as carbon whiskers that block the catalytic bed.

\section{Methods}

2.1. Density Functional Theory and Molecular Dynamic Simulations. In our simulations, we model a molten $\mathrm{NaBr}$ film (20NaBr units) supported on a $\mathrm{Ni}(111)$ slab; thus, liquid $\mathrm{NaBr}$ has one $\mathrm{NaBr}-\mathrm{Ni}(111)$ interface and one vacuum-NaBr interface. The Ni slab consists of a $4 \times 4$ rectangular Ni(111) surface cell and a thickness of three atomic layers where the bottom layer is fixed. The $\mathrm{NaBr}-\mathrm{Ni}(111)$ system is investigated using AIMD simulations, implemented in the VASP computational package ${ }^{31-34}$ and using the Nosé thermostat to sample the NVT ensemble. ${ }^{35-36}$ The motion of the atoms is treated classically, and 1 fs time steps are used to solve the Nosé equations of motion. The Nosé thermostat was set to keep the temperature around $1300 \mathrm{~K}$. The energy in these simulations is obtained by DFT, using a plane wave basis set with $350 \mathrm{eV}$ energy cutoff, and a $(2 \times 2 \times 1)$ Monkhorst-Pack $k$-point grid to sample reciprocal space. For the Bader ${ }^{37-40}$ charge analysis performed in this study we used a plane wave basis set with $400 \mathrm{eV}$ energy cutoff, and a $(4 \times 4 \times 1)$ Monkhorst-Pack $k$-point grid. The PBE functional ${ }^{41}$ and D3 van der Waals correction ${ }^{42}$ were used to approximate the exchange-correlation effects. The calculations use the projector augmented-wave method ${ }^{43-44}$ and include ten valance electrons for Ni atoms, one valance electron for $\mathrm{Na}$ atoms, seven valance electrons for $\mathrm{Br}$ atom, four valence electrons for carbon, and one valance electron for hydrogen. The remaining electrons in the atoms are treated with the frozen core approximation. Spin polarized calculations were performed for all systems; the spin charge 
density difference on $\mathrm{Ni}$ atoms range between 0.6 to $0.7 e$ (note $\mathrm{Ni}$ is known to be a ferromagnetic metal). We did not observe any spin on $\mathrm{Na}, \mathrm{Br}, \mathrm{C}$, and $\mathrm{H}$ atoms.

The mean internal energy in constant temperature AIMD is given by

$\langle E\rangle_{t}=\frac{1}{t-t_{0}} \int_{t_{0}}^{t} E(\tau) d \tau$

where $E(\tau)$ is the total internal energy at time $\tau$. Since the system is held at constant temperature, the total energy fluctuates as time evolves. The simulation prior to the time $t_{0}$ is used to equilibrate the system and is not included in the average energy. The $t_{0}$ values (Table 1 ) are chosen such that any transient in the internal energy is removed. The AIMD simulations are subsequent sampled for $t-t_{0}$ (Table 1$)$ to converge the mean internal energies.

Table 1: $t_{0}$ and $t-t_{0}$ values for the discussed AIMD simulations. The $t_{0}$ values are chosen to remove any transients in the internal energies and presumably bring the system to a state that is independent of the initial positions and momenta (equilibrated).

\begin{tabular}{|l|c|c|}
\hline \multicolumn{1}{|c|}{ Systems } & $\boldsymbol{t}_{\mathbf{0}}$ (ps) & t-to (ps) \\
\hline $20 \mathrm{NaBr}(l) / \mathrm{Ni}(111)$ & 6 & 26 \\
\hline $\mathrm{CH}_{4}(\mathrm{salt})+20 \mathrm{NaBr}(l) / \mathrm{Ni}(111)$ & 4 & 23 \\
\hline $3 \mathrm{H}^{*}+* \mathrm{CH}+20 \mathrm{NaBr}(l) / \mathrm{Ni}(111)$ & 6 & 16 \\
\hline $\mathrm{C}^{*}+20 \mathrm{NaBr}(l) / \mathrm{Ni}(111)$ & 4 & 27 \\
\hline $\mathrm{C}(\mathrm{salt})+20 \mathrm{NaBr}(l) / \mathrm{Ni}(111)$ & 4 & 23 \\
\hline $\mathrm{C}(\mathrm{vacuum}-\mathrm{salt})+20 \mathrm{NaBr}(l) / \mathrm{Ni}(111)$ & 3 & 17 \\
\hline$* \mathrm{C}_{2}+20 \mathrm{NaBr}(l) / \mathrm{Ni}(111)$ & 7 & 17 \\
\hline $2 \mathrm{C} *+20 \mathrm{NaBr}(l) / \mathrm{Ni}(111)$ & 7 & 17 \\
\hline $\mathrm{Ni}(111)$ & & \\
\hline
\end{tabular}




\begin{tabular}{|l|l|l|}
\hline $\mathrm{C}^{*}+\mathrm{Ni}(111)$ & 14 & 15 \\
\hline
\end{tabular}

Reaction energies $(\Delta E)$ of carbon atom(s) formation, carbon dimer formation, molecular methane adsorption, and dissociated methane adsorption in $20 \mathrm{NaBr}(I) / \mathrm{Ni}(111)$ are calculated as internal energy differences and referenced to methane and hydrogen molecules in the gas phase. For example, the reaction energy of forming atomic carbon, $\Delta E{ }^{* \mathrm{C}}$, is given by eq 3 , where $\left\langle E_{*}+20 \mathrm{NaBr} / \mathrm{Ni}(111)\right\rangle_{t}$ is the mean internal energy of a carbon atom adsorbed at the $20 \mathrm{NaBr}(l) / \mathrm{Ni}(111)$ interface, $\left\langle E_{\mathrm{H}_{2}(\mathrm{~g})}\right\rangle_{t}$ is the mean energy of a hydrogen molecule in the gas phase, $\left\langle E_{20 \mathrm{NaBr} / \mathrm{Ni}(111)}\right\rangle_{t}$ is the mean energy of $20 \mathrm{NaBr}(l) / \mathrm{Ni}(111)$ without any adsorbates, and $\left\langle E_{\mathrm{CH}_{4}(\mathrm{~g})}\right\rangle_{t}$ is the mean energy of methane in the gas phase.

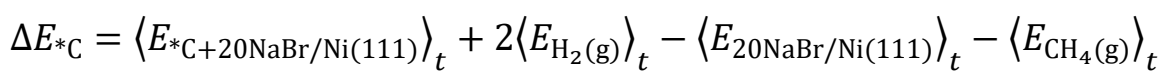

The energies of the gas phase molecules $\left(\mathrm{CH}_{4}\right.$ and $\left.\mathrm{H}_{2}\right)$ are calculated ${ }^{45}$ with the center of mass of the molecule fixed, while the molecule can rotate and vibrate. Thus, the calculations contain the electronic, classical vibrational, and classical rotational energy of the molecule in vacuum. Subsequently, the translational energy ( $3 / 2 \mathrm{k}_{\mathrm{B}} \mathrm{T}$ where $\mathrm{k}_{\mathrm{B}}$ is Boltzmann constant) is added to the energy of the gas phase molecule.

The presented AIMD simulations are computational demanding and necessitated the use of relative short simulation times, $350 \mathrm{eV}$ energy cutoff, and $(2 \times 2 \times 1)$ k-point grid. Longer simulations, higher energy cutoff, and more k-points would improve the accuracy of our simulations, however, the conclusions presented in this paper are based on energy differences of at least $0.35 \mathrm{eV}$, which we believe is larger than the possible errors from the choice of 
computational parameters (The $0.35 \mathrm{eV}$ energy difference is encountered when we compare ${ }^{*} \mathrm{C}$ adsorbed on $\mathrm{Ni}(111)$ with and without the $\mathrm{NaBr}$ fiĺm).

\section{Results and Discussion}

3.1. Structure of the molten $\mathrm{NaBr}-\mathrm{Ni}(111)$ system. We first analyze the atomic density in the molten $\mathrm{NaBr}$ film as a function height above the $\mathrm{Ni}(111)$ surface. The following procedure was applied; the molten $\mathrm{NaBr}$ film was divided into a number of imaginary strips defined by planes parallel to the surface. We count the number $n\left(N a ; z_{\alpha}, t\right)$ of $\mathrm{Na}$ atoms and the number $n\left(B r ; z_{\alpha}, t\right)$ of $\mathrm{Br}$ atoms, present at time $t$, in the strip $\alpha$, whose center is located at $z_{\alpha}$. The mean number of $\mathrm{Na}$ atoms at a distance $z_{\alpha}$ from the surface is then given by eq 4 . A similar formula is used to calculate $\left\langle n\left(B r ; z_{\alpha}\right)\right\rangle$.

$\left\langle n\left(N a ; z_{\alpha}\right)\right\rangle=\frac{1}{t-t_{0}} \int_{t_{0}}^{t} n\left(N a ; z_{\alpha}, \tau\right) d \tau$

Figure 1a shows how the concentration of $\mathrm{Na}$ and $\mathrm{Br}$ atoms varies across the molten $\mathrm{NaBr}$ film. Just above the $\mathrm{Ni}(111)$ surface there is an excess of both $\mathrm{Na}^{+}$and $\mathrm{Br}^{-}$ions, but with more $\mathrm{Na}^{+}$. This can also be seen in the movie shown in Figure S1 in the Supporting Information (SI), where the $\mathrm{Na}^{+}$(and to a lesser extend $\mathrm{Br}^{-}$) ions tend to spend more time near the $\mathrm{Ni}$ atoms. The ions, however, are not bound to the surface and they move towards and away from the $\mathrm{Ni}$ atoms at the surface over time. Slightly further from the surface $(\sim 4 \AA), \mathrm{Br}^{-}$ions have higher concentration than $\mathrm{Na}^{+}$to compensate for the higher concentration of $\mathrm{Na}^{+}$ions than $\mathrm{Br}^{-}$ions at the interface. The oscillation in $\mathrm{Na}^{+}$and $\mathrm{Br}^{-}$ion concentration continues to $\sim 10 \AA$ from the $\mathrm{Ni}(111)$ surface. Similar cation-anion interface segregations and concentration oscillations away from the surface have been observed for other molten salt-solid interfaces, namely $\mathrm{LiCl}(l) / \mathrm{MgO}(\mathrm{s})^{46}$ and $\mathrm{KCl}(l) / \mathrm{CdSe}(\mathrm{s})^{47}$ interface systems. 
The structure of a liquid is usually characterized by radial pair-distribution functions, $g_{A B}(r)$, which are defined by

$P_{A B}(r) d r=4 \pi r^{2} g_{A B}(r) \rho_{t o t} d r$

$P_{A B}(r) d r$ is the probability of finding an atom B at a distance between $\mathrm{r}$ and $\mathrm{r}+\mathrm{dr}$ from $\mathrm{A}$, and $\rho_{\text {tot }}$ is the total atomic density. Figure $1 \mathrm{~b}$ shows radial distribution functions for $20 \mathrm{NaBr}(l) / \mathrm{Ni}(111)$. The $\mathrm{Na}-\mathrm{Br}$ nearest neighbor distance peaks at $2.84 \AA$ and the nearest $\mathrm{Na}-\mathrm{Na}$, and $\mathrm{Br}-\mathrm{Br}$ distances peak at $4.13 \AA$, and $4.38 \AA$, respectively. Integration of the $\mathrm{Na}-\mathrm{Br}$ radial distribution function for distances $<4.5 \AA$ shows that every atom has an average of $\sim 5.0$ nearest neighbors.
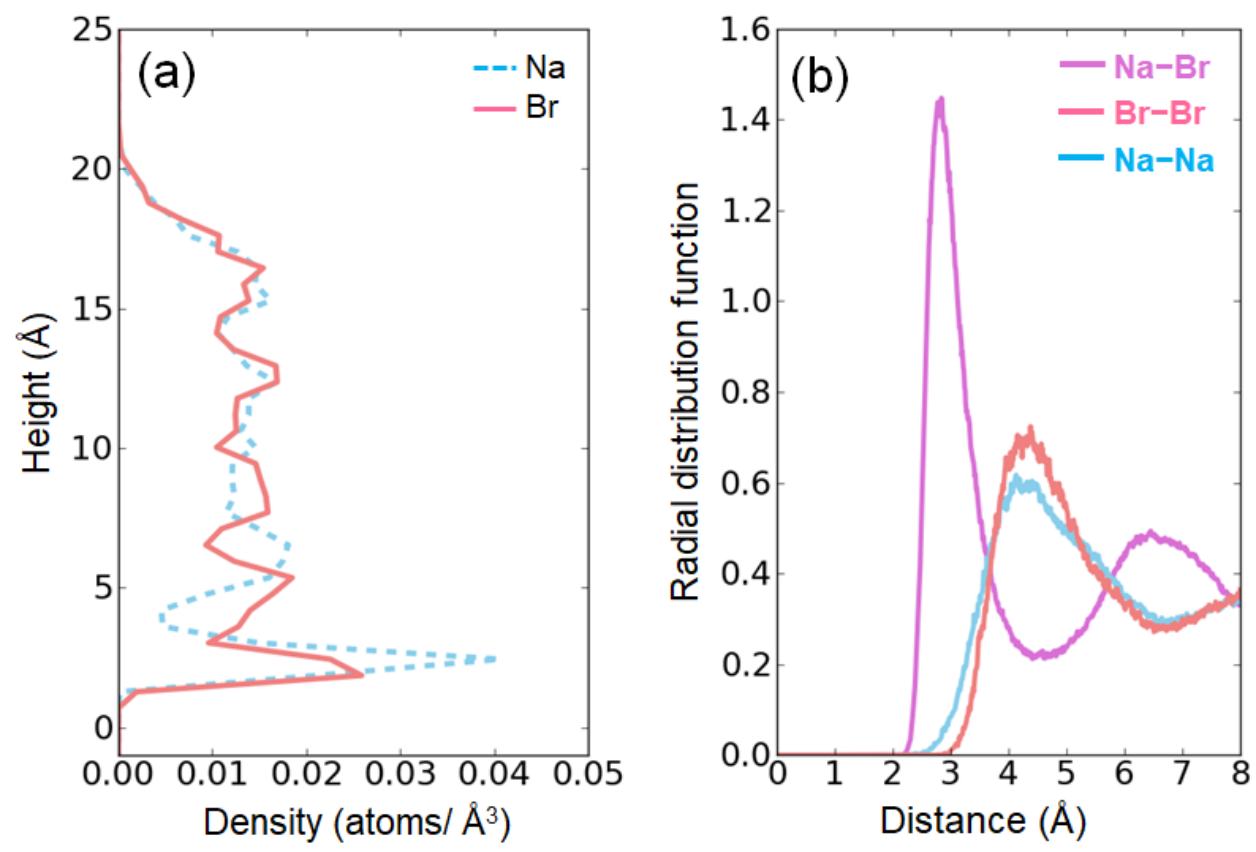

Figure 1. (a) The average concentration of $\mathrm{Na}^{+}$and $\mathrm{Br}^{-}$ions, as a function of height above the Ni(111) surface. (b) Radial distribution function versus distance for $\mathrm{Na}^{+}$and $\mathrm{Br}^{-}$ions.

3.2. Bader charge variations in $\mathrm{NaBr}-\mathrm{Ni}(111)$. In this section we analyze how the atomic Bader charges vary over time and how the Bader charges depend on distance to the Ni(111) surface. 
Figure 2a shows the time evolution of the average Bader charge on $\mathrm{Na}$ and $\mathrm{Br}$, as well as the net Bader charge in the Ni slab (48Ni). The average Bader charge on $\mathrm{Br}$ and $\mathrm{Na}$ is $-0.8 e$ and $+0.8 e$, respectively and these average values barely change over time. However, some charge transfer does take place between the salt and the Ni slab, such that the net charge in the slab is around -0.5 $e$.

We further analyze the Bader charges as a function of distance to the Ni(111) surface by plotting every individual atomic Bader charge as a function of height (Figure 2b). Here it is seen that $\mathrm{Br}^{-}$ions at the $\mathrm{NaBr}-\mathrm{Ni}(111)$ interface are less negatively charged than $\mathrm{Br}^{-}$ions further out. The missing negative charge is transferred to the surface atoms of the Ni slab and, to much lesser extent, to $\mathrm{Na}^{+}$ions at the $\mathrm{NaBr}-\mathrm{Ni}(111)$ interface. The charge transfer from $\mathrm{Br}^{-}$to the $\mathrm{Ni}$ slab is likely due to interactions between the $\mathrm{Br}^{-}$ions and the Ni surface that are covalent in nature $\left(\mathrm{Na}^{+}\right.$ ions do not seem to interact covalently with the Ni surface). As the ions get further from the surface, the Bader charge becomes constant.

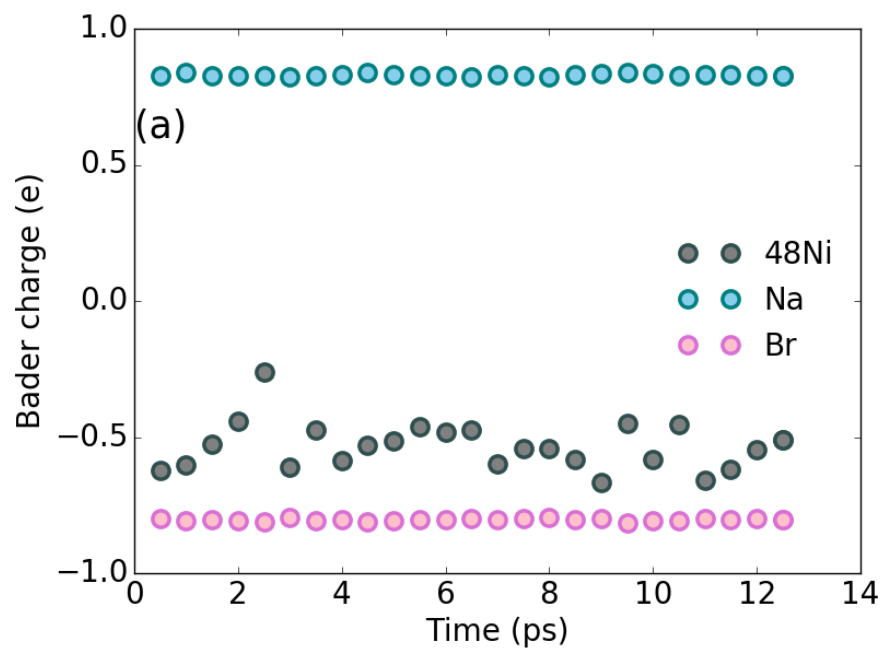




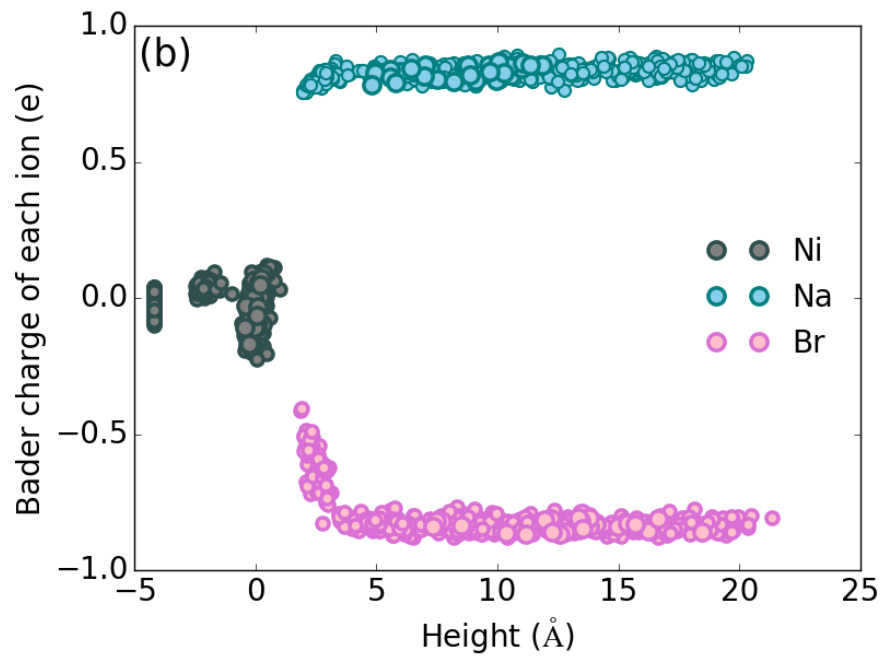

Figure 2. (a) Time evolution of the net Bader charge on the Ni slab (48Ni), as well as the average Bader charge on $\mathrm{Na}^{+}$and $\mathrm{Br}^{-}$ions during the $20 \mathrm{NaBr}(l) / \mathrm{Ni}(111)$ AIMD run. (b) Bader charges on every atom at all analyzed points in time plotted as a function of height.

3.3. Molecular and dissociated methane at the $\mathrm{NaBr}-\mathrm{Ni}(111)$ interface. Figure $3 \mathrm{a}$ shows a snapshot of molecular methane in the $\mathrm{NaBr}(l) / \mathrm{Ni}(111)$ system. The methane molecule was initially placed at the $\mathrm{NaBr}(l)-\mathrm{Ni}(111)$ interface, but the molecule dissolves into the salt after $\sim 7 \mathrm{ps,}$, (Figure $\mathrm{S} 2$ in the SI contains a movie of the entire simulation). We observe that the dissolution process is accompanied by the formation of a cavity in the $\mathrm{NaBr}$ molten salt around the methane molecule. Inside the cavity the methane molecule rotates almost freely. Since formation of the cavity increases the distances between the ions and weakens the electrostatic interactions, the solvation energy of methane in the salt becomes unfavorable compared to gas phase methane $(+1.26 \mathrm{eV}$, Table 2). Similar cavity formation has already been observed around ethane, ethylene, and $\mathrm{O}_{2}$ molecules situated at a molten $\mathrm{LiCl}-\mathrm{MgO}$ interface. ${ }^{46} \mathrm{In}$ the $\mathrm{LiCl}-\mathrm{MgO}$ system, the cavities were located at the LiCl-MgO interface, whereas we observe that the methane molecule together with the cavity is situated away from the $\mathrm{Ni}$ surface inside the molten $\mathrm{NaBr}$ film. This indicates that it 
is more favorable to disrupt ionic interactions in the molten $\mathrm{NaBr}$ salt than to disrupt $\mathrm{NaBr}-\mathrm{Ni}$ interactions at the interface.
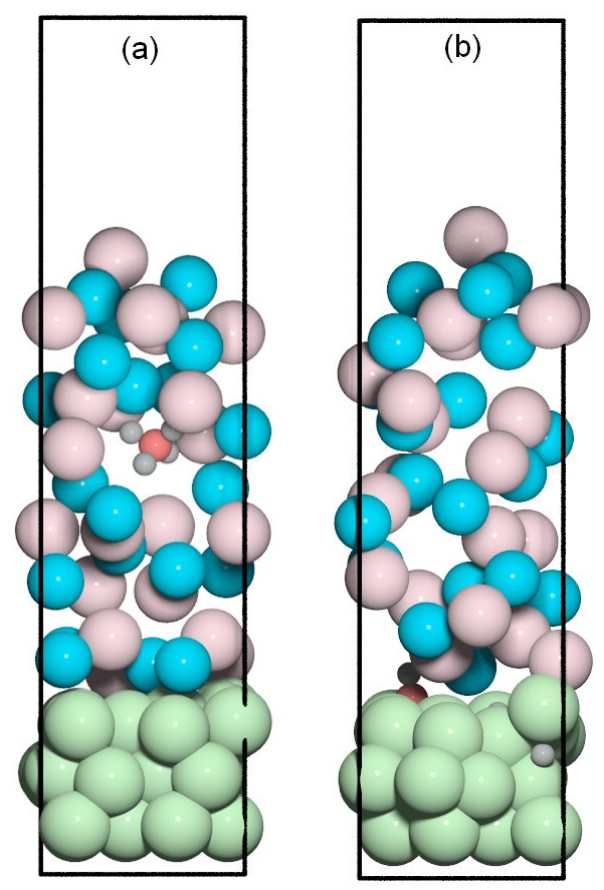

Figure 3. (a) Snapshot of a methane molecule that was initially placed at the $\mathrm{NaBr}-\mathrm{Ni}(111)$ interface, but dissolved in salt after $\sim 7$ ps of AIMD simulations. The solvation energy is $+1.26 \mathrm{eV}$. (b) Snapshot of dissociated methane $\left(3 \mathrm{H}^{*}+{ }^{*} \mathrm{CH}\right)$ at the interface of $\mathrm{NaBr}-\mathrm{Ni}(111)$ after $18 \mathrm{ps}$ of AIMD simulations. In the figures, $\mathrm{Ni}$ atoms, $\mathrm{Na}$ and $\mathrm{Br}$ ions, are shown by green, blue and pink, respectively, while carbon and hydrogens are shown by red and gray, respectively.

We also study dissociated methane $\left(3 \mathrm{H}^{*}+{ }^{*} \mathrm{CH}\right)$ adsorbed on the $\mathrm{NaBr}-\mathrm{Ni}(111)$ interface (Figure 3b) and compare the energy to the energy of methane in the gas phase (Table 2). We note that we initially inserted $\mathrm{H}^{*}+{ }^{*} \mathrm{CH}_{3}$ at the interface of $\mathrm{NaBr}-\mathrm{Ni}(111)$, but after $\sim 4 \mathrm{ps}$ of AIMD simulations ${ }^{*} \mathrm{CH}_{3}$ dissociates and form ${ }^{*} \mathrm{CH}$; apparently $3 \mathrm{H}^{*}+{ }^{*} \mathrm{CH}$ does not undergo further reaction within the time of the AIMD simulation. It has previously been found that breaking the $\mathrm{C}-\mathrm{H}$ bond in ${ }^{*} \mathrm{CH}$ 
on $\mathrm{Ni}(111)$ has a higher activation energy than breaking any of the former $\mathrm{C}-\mathrm{H}$ bonds (i.e. the ones in ${ }^{*} \mathrm{CH}_{4},{ }^{*} \mathrm{CH}_{3}$, and $\left.{ }^{*} \mathrm{CH}_{2}\right) .{ }^{48}$ Dissociative methane adsorption in the form of $3 \mathrm{H}^{*}$ and $* \mathrm{CH}$ at the $20 \mathrm{NaBr}(l) / \mathrm{Ni}(111)$ interface is uphill and the internal adsorption energy is calculated to be +0.72 $\mathrm{eV}$. Interestingly, the dissociative methane adsorption energy of $\mathrm{H}^{*}+{ }^{*} \mathrm{CH}_{3}$ and $3 \mathrm{H}^{*}+{ }^{*} \mathrm{CH}$ on $\mathrm{Ni}(111)$ without salt is $-0.39 \mathrm{eV}$ and $-0.64 \mathrm{eV}$, respectively (obtained by geometry optimized DFT calculations instead of AIMD). The destabilization of the adsorption energy for dissociated methane $\left(3 \mathrm{H}^{*}+{ }^{*} \mathrm{CH}\right)$ in the presence of molten salt is likely due to competitive adsorption at the interface, where $* \mathrm{CH}$ and $3 \mathrm{H}^{*}$ displaces $\mathrm{NaBr}$ from the surface leading to energy cost. Similar destabilization of adsorption energies have been observed for $\mathrm{HCl}$ adsorption at a water- $\mathrm{TiO}_{2}(110)$ interface ${ }^{49}$ and for $\mathrm{N}_{2}$ adsorption at the interface between $\mathrm{NaCl}$ and small $\mathrm{Ru}$ clusters. ${ }^{50}$ Even though the dissociated methane is significantly destabilized by the molten $\mathrm{NaBr}$, the adsorption energy is still significantly more stable than the methane solvation energy in the molten $\mathrm{NaBr}$ film $(1.26 \mathrm{eV})$ and dissociative methane adsorption $\left(\mathrm{H}^{*}+{ }^{*} \mathrm{CH}_{3}\right)$ on a molten $\mathrm{Cu}-\mathrm{Bi}$ surface $(1.78 \mathrm{eV})$ recently studied by us, ${ }^{51}$ where we also found that the $\mathrm{Cu}-\mathrm{Bi}$ alloy is very active for methane pyrolysis. This indicate that the presence of the molten $\mathrm{NaBr}$ film will lower the rate of methane activation (C-H bond breaking) on the $\mathrm{Ni}(111)$ surface, but probably not below what is required for high methane pyrolysis activity.

Table 2: Internal reaction energies for molecular methane and dissociated methane initially placed at the $\mathrm{NaBr}-\mathrm{Ni}(111)$ interface compared to gas phase methane. Molecular methane diffuses into the salt, while dissociated methane $\left(3 \mathrm{H}^{*}+{ }^{*} \mathrm{CH}\right)$ prefers to stay at the $\mathrm{NaBr}-\mathrm{Ni}(111)$ interface.

\begin{tabular}{|c|c|}
\hline \multicolumn{1}{|c|}{ Reactions } & $\Delta \boldsymbol{E}(\mathbf{e V})$ \\
\hline $\mathrm{CH}_{4}(\mathrm{~g})+20 \mathrm{NaBr}(l) / \mathrm{Ni}(111) \rightarrow \mathrm{CH}_{4}($ salt $)+20 \mathrm{NaBr}(l) / \mathrm{Ni}(111)$ & 1.26 \\
\hline
\end{tabular}




$$
\begin{array}{|l|l|}
\hline \mathrm{CH}_{4}(\mathrm{~g})+20 \mathrm{NaBr}(l) / \mathrm{Ni}(111) \rightarrow 3 \mathrm{H}^{*}+* \mathrm{CH}+20 \mathrm{NaBr}(l) / \mathrm{Ni}(111) & 0.72
\end{array}
$$

3.4. Single carbon atom at $\mathrm{Ni}(111)$, in $\mathrm{NaBr}$, and at vacuum-NaBr. We also computed the stability of a single carbon atom at different positions in the $\mathrm{NaBr}-\mathrm{Ni}(111)$ system. We use eq 3 to compare the energy of the atomic carbon and hydrogen gas to that of methane. The carbon atom is placed at the $\mathrm{NaBr}-\mathrm{Ni}(111)$ interface $\left(\mathrm{C}^{*}\right)$, in the salt $(\mathrm{C}($ salt $))$, and at the interface between salt and vacuum $\left(\mathrm{C}\right.$ (vacuum-salt)). Interestingly, we observe that the $\mathrm{C}^{*}$ carbon atom initially placed at the $\mathrm{NaBr}-\mathrm{Ni}(111)$ interface, diffuses into the Ni slab after $5 \mathrm{ps}$ of simulation time and remains situated between the first and second Ni layer for the rest of the simulation (we discuss diffusion into the Ni slab in section 3.6.). The reaction energies to form atomic carbon are summarized in Table 3. The reaction energies show that the $\mathrm{C}^{*}$ species in the Ni slab is by far the most stable carbon species with C(salt) being $5.73 \mathrm{eV}$ less stable and C(vacuum-salt) being $5.39 \mathrm{eV}$ less stable. Thus, for studying a carbon dimer and two separate carbon atoms, we only focus on the $\mathrm{NaBr}$ $\mathrm{Ni}(111)$ interface and the Ni slab. The internal reaction energy cost to form the $\mathrm{C}^{*}$ species in the $\mathrm{Ni}$ slab and $2 \mathrm{H}_{2}(\mathrm{~g})$ from $\mathrm{CH}_{4}(\mathrm{~g})$ is $1.64 \mathrm{eV}$. The energy cost may seem large, but note that at 1300 $\mathrm{K}$ the entropy gain $\left(-\mathrm{T} \Delta \mathrm{S}^{0}\right)$ of forming $2 \mathrm{H}_{2}(\mathrm{~g})$ and solid carbon (graphite), while consume one $\mathrm{CH}_{4}(\mathrm{~g})$ is $-1.50 \mathrm{eV}$ (https://janaf.nist.gov).

Table 3: Internal reaction energies for methane pyrolysis on $20 \mathrm{NaBr} / \mathrm{Ni}(111)$, where the carbon atom is placed at the $\mathrm{NaBr}-\mathrm{Ni}(111)$ interface but diffuses into the $\mathrm{Ni}$ slab $\left(\mathrm{C}^{*}\right)$, is placed in the molten salt $(\mathrm{C}($ salt $))$, or is placed at the vacuum- $\mathrm{NaBr}$ interface $(\mathrm{C}($ vacuum-salt $))$.

\begin{tabular}{|c|c|}
\hline \multicolumn{1}{|c|}{ Reactions } & $\Delta \boldsymbol{E}(\mathbf{e V})$ \\
\hline $\mathrm{CH}_{4}(g)+20 \mathrm{NaBr}(l) / \mathrm{Ni}(111) \rightarrow \mathrm{C}^{*}+20 \mathrm{NaBr}(l) / \mathrm{Ni}(111)+2 \mathrm{H}_{2}(g)$ & 1.64 \\
\hline
\end{tabular}




\begin{tabular}{|l|c|}
\hline $\mathrm{CH}_{4}(g)+20 \mathrm{NaBr}(l) / \mathrm{Ni}(111) \rightarrow \mathrm{C}($ salt $)+20 \mathrm{NaBr}(l) / \mathrm{Ni}(111)+2 \mathrm{H}_{2}(g)$ & 7.37 \\
\hline $\mathrm{CH}_{4}(g)+20 \mathrm{NaBr}(l) / \mathrm{Ni}(111) \rightarrow \mathrm{C}($ vacuum-salt $)+20 \mathrm{NaBr}(l) / \mathrm{Ni}(111)+2 \mathrm{H}_{2}(g)$ & 7.03 \\
\hline
\end{tabular}

3.5. Carbon dimer and carbon atoms at $\mathrm{Ni(111).} \mathrm{In} \mathrm{order} \mathrm{to} \mathrm{estimate} \mathrm{the} \mathrm{affinity} \mathrm{for} \mathrm{carbon}$ atoms to agglomerate, we initialize a carbon $\operatorname{dimer}\left({ }^{*} \mathrm{C}_{2}\right)$ at the $20 \mathrm{NaBr}(l) / \mathrm{Ni}(111)$ interface and compare the dimer to two separate carbon atoms $\left(2 \mathrm{C}^{*}\right)$ also initially placed at the $20 \mathrm{NaBr}(l) / \mathrm{Ni}(111)$ interface. The carbon-carbon distances as a function of time for both the carbon dimer and the two separate carbon atoms are shown in Figure 4. The carbon-carbon bond distance in the carbon dimer vibrates between $1.4 \AA-1.5 \AA$, for the first 20 ps of simulation time, however, the carbon dimer then dissociates and the distance increases to more than $3 \AA$ (Figure $4 \mathrm{a}$ ). Oppositely, the two separate carbon atoms never get closer than $2.4 \AA$ and do not form a chemical bond at any point in time (Figure 4b). The atomic configuration for the carbon dimer at the interface after 5 ps and 25 ps of AIMD simulation time is shown in Figure 5. After 5 ps the carbon dimer is clearly visible and adsorbed on the Ni(111) surface, whereas, after $25 \mathrm{ps,} \mathrm{the} \mathrm{carbon} \mathrm{dimer}$ has dissociated into two separate carbon atoms. Furthermore, we see that the carbon atoms from the carbon dimer have moved into the Ni slab and are now situated between the first and second layer. The two separate carbon atoms also migrate into the Ni slab during their AIMD simulation. 

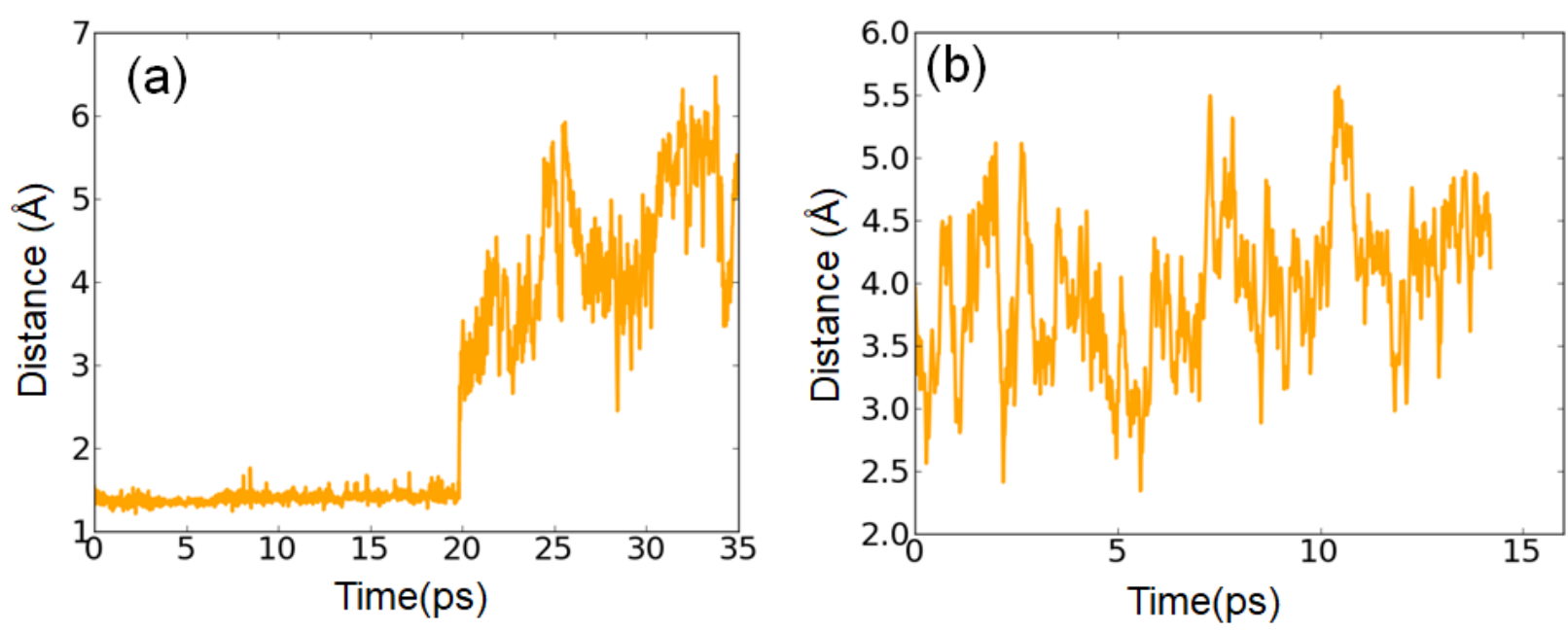

Figure 4. Distance between the two carbon atoms for (a) carbon dimer and (b) two separate carbon atoms. The carbon dimer dissociates after 20 ps, whereas the two carbon atoms do not get close enough to form a bond.

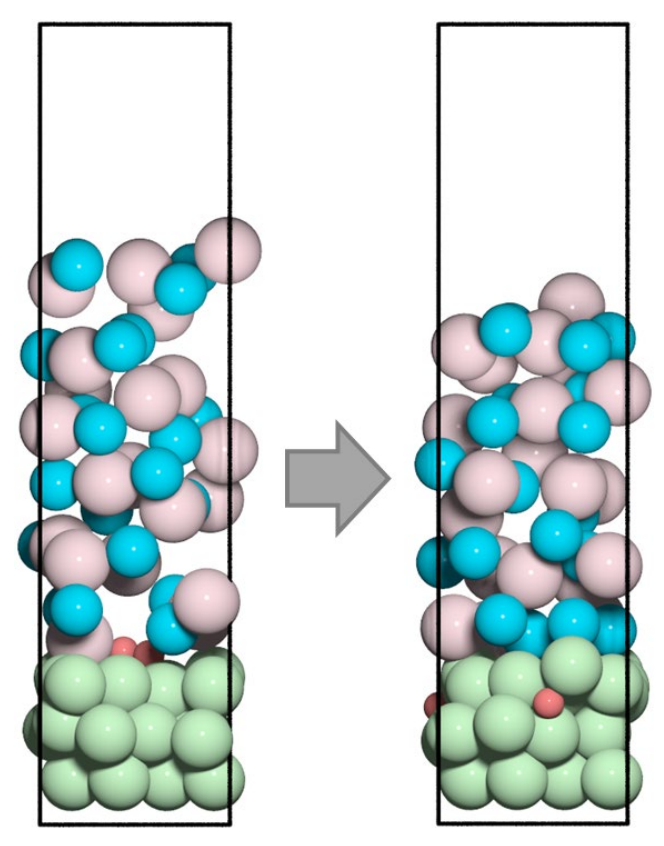

Figure 5. Atomic configuration of the ${ }^{*} \mathrm{C}_{2}+20 \mathrm{NaBr}(l) / \mathrm{Ni}(111)$ interface (i.e. the carbon dimer simulation) after 5 ps and 25 ps. The carbon dimer dissociates and diffuses into the Ni slab over 
time. In the figure $\mathrm{Ni}$ atoms are shown in green, while $\mathrm{Na}$ and $\mathrm{Br}$ ions are shown in blue and pink, respectively.

Table 4 compares the energy of the carbon dimer $\left({ }^{*} \mathrm{C}_{2}\right)$ to that of two separate carbon atoms $\left(2 \mathrm{C}^{*}\right)$. Since the carbon dimer dissociates into two separate carbon atoms after $20 \mathrm{ps,}$, the energy sampling is only conducted for the part of the simulation where the carbon dimer is intact. The energy of the two separate carbon atoms is $0.86 \mathrm{eV}$ more stable than the energy of the carbon dimer. Based on this energy difference and the observed carbon dimer dissociation, we conclude that carbon atoms prefer to stay separated rather than agglomerating into dimers. Finally, we note that the energy of two carbon atoms at the $\mathrm{NaBr}(l) / \mathrm{Ni}(111)$ interface $(3.45 \mathrm{eV})$ is only slightly higher than twice the energy of a single carbon atom at the $\mathrm{NaBr}(l) / \mathrm{Ni}(111)$ interface $(2 \times 1.64 \mathrm{eV})$. The small difference likely corresponds to a repulsion that occur between the two carbon atoms.

Table 4: Internal reaction energies for methane pyrolysis to form carbon dimer and two separate carbon atoms initially placed at the $20 \mathrm{NaBr}(l) / \mathrm{Ni}(111)$ interface.

\begin{tabular}{|c|c|}
\hline \multicolumn{1}{|c|}{ Reactions } & $\Delta \boldsymbol{E}(\mathbf{e V})$ \\
\hline $2 \mathrm{CH}_{4}(\mathrm{~g})+20 \mathrm{NaBr}(l) / \mathrm{Ni}(111) \rightarrow{ }^{*} \mathrm{C}_{2}+20 \mathrm{NaBr}(l) / \mathrm{Ni}(111)+4 \mathrm{H}_{2}(\mathrm{~g})$ & 4.31 \\
\hline $2 \mathrm{CH}_{4}(\mathrm{~g})+20 \mathrm{NaBr}(l) / \mathrm{Ni}(111) \rightarrow 2 \mathrm{C}^{*}+20 \mathrm{NaBr}(l) / \mathrm{Ni}(111)+4 \mathrm{H}_{2}(\mathrm{~g})$ & 3.45 \\
\hline
\end{tabular}

3.6. Diffusion of carbon atoms and carbon dimer into the Ni slab. As expected from the energy analysis in section 3.4, we never observe that carbon atoms diffuse from the Ni surface into the molten salt as this movement comes with a very high energy cost. However, when the molecular dynamics trajectories of the single carbon atom and carbon dimer are monitored, they show that the carbon species diffuse into the Ni slab. Figure 6 shows the height of the single carbon atom 
and the carbon dimer with respect to the top Ni layer over time. The adsorbed carbon species jump from the $\mathrm{Ni}(111)$ surface to a location in between the first and second $\mathrm{Ni}$ layer after $\sim 5 \mathrm{ps}$ for the single carbon atom (Figure $6 \mathrm{a}$ ) and after $\sim 8 \mathrm{ps}$ for the carbon dimer (Figure $6 \mathrm{~b}$ ). Since the carbon dimer doesn't dissociate into two separate carbon atoms until $20 \mathrm{ps}$, both the single carbon and the carbon dimer species are able to diffuse into the Ni slab. The carbon species never jump to a location between the second and third Ni layer and we speculate that the frozen third Ni layer prevents this from happening.
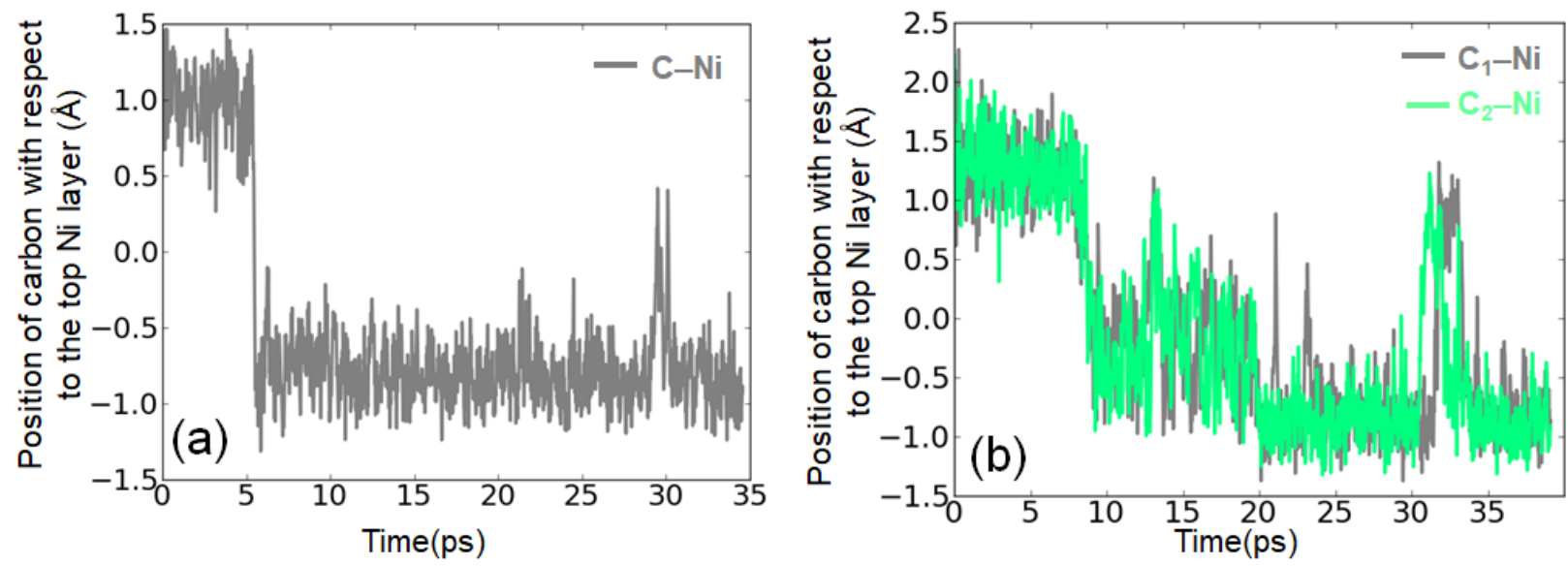

Figure 6. (a) Distance over time between the single carbon atom and the top Ni layer. (b)

Distances over time between the two carbon atoms $\left(\mathrm{C}_{1}\right.$ and $\left.\mathrm{C}_{2}\right)$ in the carbon dimer and the top Ni layer.

3.7. Effect of molten NaBr on the stability of carbon in the Ni slab. Finally, we estimate the effect of the $\mathrm{NaBr}$ melt on the stability of the single carbon atom when it is situated inside the $\mathrm{Ni}$ slab. We therefore compare the energy of forming the $\mathrm{C}^{*}$ species and $2 \mathrm{H}_{2}(\mathrm{~g})$ from $\mathrm{CH}_{4}(\mathrm{~g})$ without and with the $20 \mathrm{NaBr}(l)$ film. The reaction energy to form $\mathrm{C}^{*}$ in the $\mathrm{Ni}(111)$ slab without the molten $\mathrm{NaBr}$ film is $1.99 \mathrm{eV}$ (Figure 7a), whereas the reaction energy to from $\mathrm{C}^{*}$ in the $\mathrm{Ni}(111)$ slab with 
the $\mathrm{NaBr}$ film is $1.63 \mathrm{eV}$ (Table 3, Figure $7 \mathrm{~b}$ ). In both cases, the carbon atom was initially placed on the $\mathrm{Ni}(111)$ surface, but diffuses into $\mathrm{Ni}$ slab (even without the molten $\mathrm{NaBr}$ film). The energy difference suggests that the presence of the molten salt stabilizes the internal energy of carbon in the $\mathrm{Ni}$ subsurface region. The molten $\mathrm{NaBr}$ is therefore unlikely to prevent the $\mathrm{Ni}$ catalyst from coking or from being converted to a carbide.
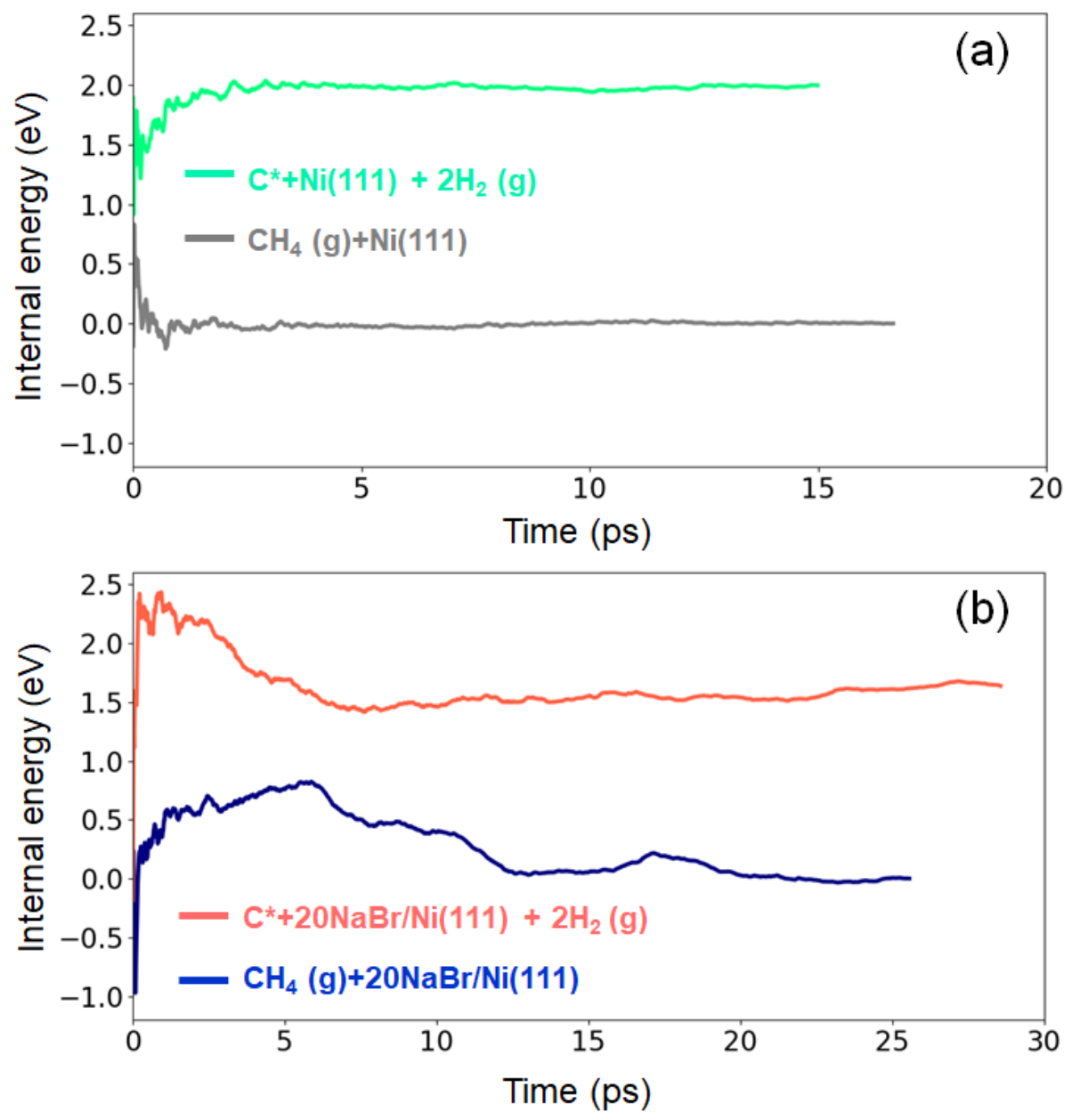

Figure 7. Cumulative mean internal energies as a function of elapsed time for (a) $2 \mathrm{H}_{2}(\mathrm{~g})+\mathrm{C}^{*}$ in $\mathrm{Ni}(111)$ and $\mathrm{CH}_{4}(\mathrm{~g})+\mathrm{Ni}(111)$ without adsorbates. (b) $2 \mathrm{H}_{2}(\mathrm{~g})+\mathrm{C}^{*}$ in $20 \mathrm{NaBr}(\mathrm{l}) / \mathrm{Ni}(111)$ and $\mathrm{CH}_{4}(\mathrm{~g})+20 \mathrm{NaBr}(l) / \mathrm{Ni}(111)$ without adsorbates. The reference states $\left(\mathrm{CH}_{4}(\mathrm{~g})+\mathrm{Ni}(111)\right.$ and 
$\left.\mathrm{CH}_{4}(\mathrm{~g})+20 \mathrm{NaBr}(l) / \mathrm{Ni}(111)\right)$ are set to $0 \mathrm{eV}$ after the full simulation time. The reaction energies are $1.99 \mathrm{eV}$ in (a) and $1.63 \mathrm{eV}$ in (b).

\section{Summary and Conclusions}

The presence of the molten $\mathrm{NaBr}$ film influences the properties of the $\mathrm{Ni}(111)$ surface in several interesting ways. Bader charge analysis shows that negative charge is transferred from $\mathrm{Br}^{-}$ions at the $\mathrm{NaBr}-\mathrm{Ni}(111)$ interface to the $\mathrm{Ni}(111)$ slab. The net charge in the $\mathrm{Ni}$ slab is found to be $\sim-0.5$ $e$. With regard to methane pyrolysis, methane solvated in the $\mathrm{NaBr}$ film is less stable than gas phase methane. Additionally, dissociated methane adsorbed at the $\mathrm{NaBr}-\mathrm{Ni}(111)$ interface is less stable than dissociated methane adsorbed on $\mathrm{Ni}(111)$ without $\mathrm{NaBr}$. However, this may not be a problem, as both situations are more stable than dissociated methane adsorbed on molten $\mathrm{Cu}-\mathrm{Bi}$ alloys, which are known to be active for methane pyrolysis. Carbon atoms at the $\mathrm{NaBr}-\mathrm{Ni}(111)$ interface are unlikely to agglomerate, since carbon dimers are thermodynamically and kinetically unstable. Carbon atoms placed at the at the $\mathrm{NaBr}-\mathrm{Ni}(111)$ interface do not stay at the interface, but diffuse into the Ni slab. The stability of carbon atoms in the subsurface region of the Ni(111) slab is increased by the presence of molten $\mathrm{NaBr}$.

We had hoped that the molten $\mathrm{NaBr}$ would wash carbon of the $\mathrm{Ni}(111)$ surface, for instance by dissolving the carbon in the molten salt, but our study shows that this does not happen. Instead, the molten $\mathrm{NaBr}$ may help keep the $\mathrm{Ni}(111)$ surface free of carbon and catalytically active by stabilizing subsurface carbon. The dissolved carbon will eventually precipitate out of the nickel

particles and form solid carbon. The behavior of that carbon will determine whether dissolving carbon in the nickel particles is a desirable way to remove coke.

\section{Supporting Information}


Movie of the $20 \mathrm{NaBr}(l) / \mathrm{Ni}(111)$ trajectory showing the movement of $\mathrm{Na}^{+}$and $\mathrm{Br}^{-}$ions above the $\mathrm{Ni}$ (111) surface; movie of the $\mathrm{CH}_{4}($ salt $)+20 \mathrm{NaBr}(l) / \mathrm{Ni}(111)$ trajectory showing the dissolution of methane into the salt; movie of the ${ }^{*} \mathrm{C}_{2}+20 \mathrm{NaBr}(l) / \mathrm{Ni}(111)$ trajectory showing diffusion of ${ }^{*} \mathrm{C}_{2}$ into $\mathrm{Ni}(111)$ and subsequent dissociation into $2 \mathrm{C}^{*}$; cumulative mean internal energy plots as a function of elapsed time for molecular methane and dissociated methane initially placed at the $\mathrm{NaBr}-\mathrm{Ni}(111)$ interface, compared to gas phase methane; cumulative mean internal energy plot of methane pyrolysis on $20 \mathrm{NaBr} / \mathrm{Ni}(111)$ as a function of elapsed time, where the carbon atom is placed at the $\mathrm{NaBr}-\mathrm{Ni}(111)$ interface, in the molten salt, or at the vacuum- $\mathrm{NaBr}$ interface; cumulative mean internal energy plot of methane pyrolysis as a function of elapsed time to form carbon dimer and two separate carbon atoms initially placed at the $\mathrm{NaBr}-\mathrm{Ni}(111)$ interface.

Acknowledgments. This work was primarily supported by the Energy \& Biosciences Institute through the EBI-Shell program and the U.S. Department of Energy, Office of Science Basic Energy Sciences, grant no. DE-FG03-89ER14048. Use was made of computational facilities purchased with funds from the National Science Foundation (CNS-1725797) and administered by the Center for Scientific Computing (CSC). The CSC is supported by the California NanoSystems Institute and the Materials Research Science and Engineering Center (MRSEC; NSF DMR 1720256) at UC Santa Barbara.

\section{References}

1. Choudhary, T. V.; Aksoylu, E.; Goodman, D. W., Nonoxidative activation of methane. Catal. Rev.: Sci. Eng. 2003, 45, 151-203.

2. Li, Y.; Li, D.; Wang, G., Methane decomposition to $\mathrm{CO}_{x}$-free hydrogen and nano-carbon material on group 8-10 base metal catalysts: A review. Catal. Today 2011, 162, 1-48.

3. Holladay, J. D.; Hu, J.; King, D. L.; Wang, Y., An overview of hydrogen production technologies. Catal. Today 2009, 139, 244-260. 
4. Abánades, A.; Rathnam, R. K.; Geißler, T.; Heinzel, A.; Mehravaran, K.; Müller, G.; Plevan, M.; Rubbia, C.; Salmieri, D.; Stoppel, L.; et al., Development of methane decarbonisation based on liquid metal technology for $\mathrm{CO}_{2}$-free production of hydrogen. Int. J. Hydrogen Energy 2016, 41, 8159-8167.

5. Abanades, S.; Flamant, G., Solar hydrogen production from the thermal splitting of methane in a high temperature solar chemical reactor. Sol. Energy 2006, 80, 1321-1332.

6. Abanades, S.; Flamant, G., High-temperature solar chemical reactors for hydrogen production from natural gas cracking. Chem. Eng. Commun. 2008, 195, 1159-1175.

7. Geissler, T.; Abanades, A.; Heinzel, A.; Mehravaran, K.; Muller, G.; Rathnam, R. K.; Rubbia, C.; Salmieri, D.; Stoppel, L.; Stuckrad, S.; et al., Hydrogen production via methane pyrolysis in a liquid metal bubble column reactor with a packed bed. Chem. Eng. J. 2016, 299, 192-200.

8. Geißler, T.; Plevan, M.; Abánades, A.; Heinzel, A.; Mehravaran, K.; Rathnam, R. K.; Rubbia, C.; Salmieri, D.; Stoppel, L.; Stückrad, S.; et al., Experimental investigation and thermo-chemical modeling of methane pyrolysis in a liquid metal bubble column reactor with a packed bed. Int. J. Hydrogen Energy 2015, 40, 14134-14146.

9. Muradov, N., Hydrogen via methane decomposition: an application for decarbonization of fossil fuels. Int. J. Hydrogen Energy 2001, 26, 1165-1175.

10. Muradov, N., Catalysis of methane decomposition over elemental carbon. Catal. Commun. 2001, 2, 89-94.

11. Muradov, N., Low to near-zero $\mathrm{CO}_{2}$ production of hydrogen from fossil fuels: Status and perspectives. Int. J. Hydrogen Energy 2017, 42, 14058-14088.

12. Muradov, N.; Smith, F.; Huang, C.; T-Raissi, A., Autothermal catalytic pyrolysis of methane as a new route to hydrogen production with reduced $\mathrm{CO}_{2}$ emissions. Catal. Today 2006, 116, 281-288.

13. Muradov, N.; Smith, F.; T-Raissi, A., Catalytic activity of carbons for methane decomposition reaction. Catal. Today 2005, 102, 225-233.

14. Muradov, N. Z., How to produce hydrogen from fossil fuels without $\mathrm{CO}_{2}$ emission. Int. J. Hydrogen Energy 1993, 18, 211-215.

15. Muradov, N. Z. Thermocatalytic process for $\mathrm{CO}_{2}$ free production of hydrogen and carbon from hydrocarbons. US 6,670052 2003.

16. Muradov, N. Z.; Veziroğlu, T. N., From hydrocarbon to hydrogen-carbon to hydrogen economy. Int. J. Hydrogen Energy 2005, 30, 225-237.

17. Muradov, N. Z.; Veziroğlu, T. N., "Green" path from fossil-based to hydrogen economy: An overview of carbon-neutral technologies. Int. J. Hydrogen Energy 2008, 33, 6804-6839.

18. Plevan, M.; Geißler, T.; Abánades, A.; Mehravaran, K.; Rathnam, R. K.; Rubbia, C.; Salmieri, D.; Stoppel, L.; Stückrad, S.; Wetzel, T., Thermal cracking of methane in a liquid metal bubble column reactor: Experiments and kinetic analysis. Int. J. Hydrogen Energy 2015, 40, 8020-8033.

19. Postels, S.; Abánades, A.; von der Assen, N.; Rathnam, R. K.; Stückrad, S.; Bardow, A., Life cycle assessment of hydrogen production by thermal cracking of methane based on liquid-metal technology. Int. J. Hydrogen Energy 2016, 41, 23204-23212.

20. Serban, M.; Lewis, M. A.; Marshall, C. L.; Doctor, R. D., Hydrogen Production by Direct Contact Pyrolysis of Natural Gas. Energy Fuels 2003, 17, 705-713.

21. Steinberg, M., The Hy-C process (thermal decomposition of natural gas) potentially the lowest cost source of hydrogen with the least $\mathrm{CO}_{2}$ emission. Energy Convers. Manag. 1995, 36, 791-796.

22. Steinberg, M., Production of hydrogen and methanol from natural gas with reduced $\mathrm{CO}_{2}$ emission. Int. J. Hydrogen Energy 1998, 23, 419-425.

23. Steinberg, M., Fossil fuel decarbonization technology for mitigating global warming. Int. J. Hydrogen Energy 1999, 24, 771-777. 
24. Upham, D. C.; Agarwal, V.; Khechfe, A.; Snodgrass, Z. R.; Gordon, M. J.; Metiu, H.; McFarland, E. W., Catalytic molten metals for the direct conversion of methane to hydrogen and separable carbon. Science 2017, 358, 917-921.

25. Palmer, C.; Tarazkar, M.; Kristoffersen, H. H.; Gelinas, J.; Gordon, M. J.; McFarland, E. W.; Metiu, H., Methane Pyrolysis with a Molten Cu-Bi Alloy Catalyst. ACS Catal. 2019, 9, 8337-8345.

26. Kang, D.; Rahimi, N.; Gordon, M. J.; Metiu, H.; McFarland, E. W., Catalytic methane pyrolysis in molten $\mathrm{MnCl}_{2}-\mathrm{KCl}$. Appl. Catal. B Environ. 2019, 254, 659-666.

27. Zeng, J.; Tarazkar, M.; Tyler Pennebacker; Gordon, M. J.; Metiu, H.; McFarland, E. W., Catalytic methane pyrolysis with liquid and vapor phase tellurium. ACS Catal. 2020, 10, 8223-8230.

28. Trimm, D. L., Catalysts for the control of coking during steam reforming. Catal. Today 1999, 49, 3-

10.

29. Browning, L. C.; Emmett, P. H., Equilibrium Measurements in the $\mathrm{Ni}_{3} \mathrm{C}-\mathrm{Ni}-\mathrm{CH}_{4}-\mathrm{H}_{2}$ and $\mathrm{Co}_{2} \mathrm{C}-$ Co- $\mathrm{CH}_{4}-\mathrm{H}_{2}$ Systems. J. Am. Chem. Soc. 1952, 74, 1680-1682.

30. Meyer, G.; Scheffer, F. E. C., The Properties of Nickel Carbide. J. Am. Chem. Soc. 1953, 75, 486486.

31. Kresse, G.; Hafner, J., Ab initio molecular-dynamics simulation of the liquid-metal-amorphoussemiconductor transition in germanium. Phys. Rev. B 1994, 49, 14251-14269.

32. Kresse, G., Ab initio molecular dynamics for liquid metals. J. Non-Cryst. Solids 1995, 192-193, 222229.

33. Kresse, G.; Furthmüller, J., Efficiency of ab-initio total energy calculations for metals and semiconductors using a plane-wave basis set. Comput. Mater. Sci. 1996, 6, $15-50$.

34. Kresse, G.; Furthmüller, J., Efficient iterative schemes for ab initio total-energy calculations using a plane-wave basis set. Phys. Rev. B 1996, 54 , 11169-11186.

35. Nosé, S., A molecular dynamics method for simulations in the canonical ensemble. Mol. Phys. 1984, 52, 255-268.

36. Nosé, S., A unified formulation of the constant temperature molecular dynamics methods. J. Chem. Phys. 1984, 81, 1984.

37. Henkelman, G.; Arnaldsson, A.; Jónsson, H., A fast and robust algorithm for Bader decomposition of charge density. Comput. Mater. Sci. 2006, 36, 354-360.

38. Sanville, E.; Kenny, S.; Smith, R.; Henkelman, G., An Improved Grid-Based Algorithm for Bader Charge Allocation. J. Comput. Chem. 2007, 28, 899-908.

39. Tang, W.; Sanville, E.; Henkelman, G., A Grid-Based Bader Analysis Algorithm Without Lattice Bias. J. Phys. Condens. Matter 2009, 21, 084204.

40. Yu, M.; Trinkle, D. R., Accurate and efficient algorithm for Bader charge integration J. Chem. Phys. 2011, 134, 064111.

41. Perdew, J. P.; Burke, K.; Ernzerhof, M., Generalized Gradient Approximation Made Simple. Phys. Rev. Lett. 1996, 77, 3865-3868.

42. Grimme, S.; Antony, J.; Ehrlich, S.; Krieg, H., A consistent and accurate ab initio parametrization of density functional dispersion correction (DFT-D) for the 94 elements H-Pu. J. Chem. Phys. 2010, 132, 154104

43. Blöchl, P. E., Projector augmented-wave method. Phys. Rev. B 1994, 50, 17953-17979.

44. Kresse, G. J.; Joubert, D., From Ultrasoft Pseudopotentials to the Projector Augmented-Wave Method. Phys. Rev. B 1999, 59, 1758-1775.

45. Kristoffersen, H. H.; Metiu, H., Chemistry of Solvated Electrons in Molten Alkali Chloride Salts. J. Phys. Chem. C 2018, 122, 19603-19612.

46. Kristoffersen, H. H.; Metiu, H., Molten LiCl Layer Supported on MgO: Its Possible Role in Enhancing the Oxidative Dehydrogenation of Ethane. J. Phys. Chem. C 2015, 119, 8681-8691. 
47. Zhang, H.; Dasbiswas, K.; Ludwig, N. B.; Han, G.; Lee, B.; Vaikuntanathan, S.; Talapin, D. V., Stable colloids in molten inorganic salts. Nature 2017, 542, 328.

48. S. Roy, S. Hariharan, A. K. Tiwari, J. Phys. Chem. C 2018, 122, 10857-10870

49. Kristoffersen, H. H.; Shea, J.-E.; Metiu, H., Catechol and $\mathrm{HCl}$ adsorption on $\mathrm{TiO}_{2}(110)$ in vacuum and at the water-TiO ${ }_{2}$ interface. J. Phys. Chem. Lett. 2015, 6, 2277-2281.

50. Rahimi, N.; McFarland, E. W.; Metiu, H.; Kristoffersen, H. H., Properties of Negatively Charged Ruthenium Clusters in Molten Sodium Chloride, J. Phys. Chem. C 2019, 123, 16179-16185

51. Palmer, C.; Tarazkar, M.; Kristoffersen, H. H.; Gelinas, J.; Gordon, M. J.; McFarland, E. W.; Metiu, H., Methane Pyrolysis with a Molten Cu-Bi Alloy Catalyst. ACS Catal. 2019, 9, 8337-8345. 


\section{TOC Graphic}

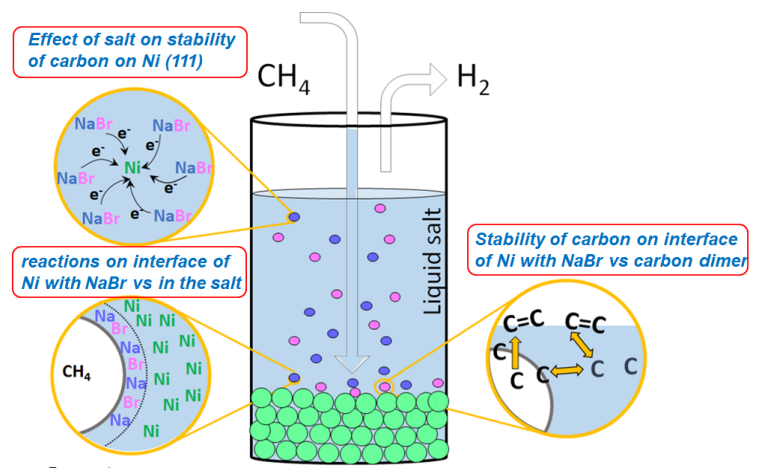

